\title{
RELAÇÕES ENTRE A PRODUÇÃO DE LARANJEIRA 'WESTIN' E AS PRECIPITAÇÕES EM BOTUCATU, SP'1
}

\author{
ANTONIO TUBELIS ${ }^{2}$, ARY APARECIDO SALIBE ${ }^{3}$ e GISLENE PESSIM ${ }^{4}$
}

\begin{abstract}
RESUMO - O trabalho estuda a correlação entre a produção de um pomar de laranja, plantado no altiplano de Botucatu, SP, com as precipitações que ocorrem dezesseis meses antes da colheita e a idade do pomar. As plantas eram de laranjeira doce (Citrus sinensis (L.) Osbeck), variedade Westin, de clone nucelar, enxertadas em porta-enxerto de limoeiro 'Cravo' (Citrus limonia Osbeck), plantadas em solo Terra Roxa Estruturada, a $810 \mathrm{~m}$ de altitude e em região de clima do tipo Cwb. A cultura foi conduzida de modo convencional e sem irrigação. Coletaram-se dados de produção, nos períodos entre o $3^{\circ}$ e o $17^{\circ}$ e entre o $21^{\circ}$ e o $27^{\circ}$ ano de idade do pomar, para análise do comportamento da produção e o efeito da idade e das precipitações na produção. Calcularam-se equações lineares múltiplas de regressão, entre a produção, idade do pomar e as precipitações mensais, nos períodos de pomar juvenil, adulto, senescente e adulto-senescente. A produção correlacionou-se com a idade e com valores mensais de precipitação. Os pequenos desvios observados entre os valores medidos e estimados de produção revelaram que as equações de regressão poderiam ser usadas na previsão de safra ou no controle de irrigação suplementar do pomar.
\end{abstract}

Termos para indexação: laranjeira doce, clima, previsão de safra, irrigação suplementar.

\section{RELATIONSHIPS BETWEEN PRODUCTION OF 'WESTIN' SWEET ORANGE TREES AND RAINFALL AT BOTUCATU, SÃO PAULO STATE, BRAZIL}

\begin{abstract}
This paper deals with the existence of correlation between the production of a sweet orange orchard, planted at the plateau of Botucatu, São Paulo State, Brazil, with the orchard age and the rainfall that occurred in the sixteen months before the picking season. The plants were of sweet orange trees (Citrus sinensis (L.) Osbeck), variety Westin, budded on 'Rangpur' lime (Citrus limonia Osbeck) rootstock, grown on "Terra Roxa Estruturada" soil, at an altitude of $810 \mathrm{~m}$ above sea level and in a region with Cwb climatic type. The orchard was conducted by conventional ways and no irrigation was applied. The production of the orchard was recorded, during the period from the $3^{\text {rd }}$ until the $17^{\text {th }}$ and from the $21^{\text {st }}$ until the $27^{\text {th }}$ year old, to analyse the behaviour of the production and the effect of the orchard age and of the rainfalls on the production of the plants. Multi linear regression equations among the production, age of the orchard and monthly rainfalls were calculated for the juvenile, adult, senescent and adult-senescent phases of the period of orchard production. The production was found to be correlated with the orchard age and with the monthly rainfalls. The small deviations between the measured and calculated values of production showed that the regression equations could be used to crop forecast or to suplemental irrigation control of the orchard.
\end{abstract}

Index terms: sweet orange tree, climate, crop forecast, suplemental irrigation.

${ }^{1}$ Aceito para publicação em 19 de agosto de 1998.

${ }^{2}$ Eng. Agr., Dr., Prof. Titular, Faculdade de Agronomia e Medicina Veterinária, UnB, Caixa Postal 04508, CEP 70910-970 Brasília, DF. Bolsista do CNPq. E-mail: atubelis@unb.br

${ }^{3}$ Eng. Agr., Dr., Dep. de Horticultura, Faculdade de Ciências Agronômicas, UNESP, Caixa Postal 237, CEP 18603-970 Botucatu, SP Bolsista do CNPq. E-mail: adsalibe@carpa.ciagri.usp.br

${ }^{4}$ Eng $\underline{\text { Agr }}$, UNESP. Bolsista do Pibic.

\section{INTRODUÇÃO}

A cultura da laranja, quando realizada sem irrigação nas condições climáticas do Estado de São Paulo, apresenta grandes variações de produção, de ano para ano. A primeira tentativa para estabelecer relações de causa e efeito, para as condições do Es- 
tado de São Paulo, foi feita por Gallo et al. (1977). Os autores estudaram o comportamento da produção anual das plantas de um pomar de laranja 'Baianinha', em Cordeirópolis, no Estado de São Paulo, em comparação com o balanço hídrico anual da região. Verificaram que deficiências hídricas anuais acentuadas não correspondiam a produções reduzidas nos anos seguintes e que excedentes hídricos elevados não causavam aumentos consistentes de produção nos mesmos anos agrícolas. $\mathrm{Na}$ África do Sul, Du Plessis (1983) mostrou que o total anual de chuva, no período de julho a junho, tinha um efeito negativo na produtividade de laranja 'Navel', em Letaba.

Nas condições do planalto paulista, Tubelis \& Salibe (1989) verificaram que a produtividade de pomares de laranja 'Hamlin' era influenciada pela natureza do porta-enxerto, pela idade do pomar e pelas precipitações mensais. Posteriormente, Tubelis \& Salibe (1992) mostraram que a produtividade de laranja 'Baianinha', quando enxertada em porta-enxerto de limoeiro 'Cravo', estava correlacionada com a idade do pomar e com precipitações mensais.

O presente trabalho visa estudar o comportamento das produções e a existência de correlação entre a produção de laranjeira 'Westin', sobre porta-enxerto de limoeiro 'Cravo', com a idade do pomar e as precipitações mensais que ocorrem dezesseis meses antes da colheita nas condições mesológicas do altiplano de Botucatu, no Estado de São Paulo.

\section{MATERIAL E MÉTODOS}

As produções de laranjeira doce foram obtidas em experimento conduzido na Fazenda Experimental Lageado, da UNESP, em Botucatu, no Estado de São Paulo. Os valores de produção, expressos em quilogramas de frutos por planta, referem-se às produções do $3 \underline{0}$ ao 170 e do $21 \stackrel{0}{\circ}$ ao 270 ano de idade de um pomar de laranjeira doce 'Westin'(Citrus sinensis (L.) Osbeck) sobre porta-enxerto de limoeiro 'Cravo' (Citrus limonia Osbeck), correspondendo às safras de 1968 a 1982 e de 1986 a 1992.

Os valores mensais de precipitação foram obtidos com pluviômetro, instalado em posto climatológico situado a $300 \mathrm{~m}$ do local do ensaio, a $810 \mathrm{~m}$ de altitude. O pomar foi plantado em 1965, em terreno de meia encosta, com $8 \%$ de declividade e exposição nascente, no espaçamento de 7 m x 7 m, em solo Terra Roxa Estruturada, em região onde o clima predominante é Cwb - clima mesotérmico úmido, com inverno seco e verão brando - segundo a classificação climática de Köppen.

O pomar foi conduzido de forma convencional, sem irrigação. O controle do mato, entre as plantas, foi efetuado com grade de discos e roçadeira e o coroamento das plantas com enxada. Todo ano, a partir de 1985, foram aplicados sobre a superfície do solo de cada planta os seguintes adubos: a) mistura de $2,0 \mathrm{~kg}$ de sulfato de amônio, $1,5 \mathrm{~kg}$ de superfosfato simples e $1,0 \mathrm{~kg}$ de cloreto de potássio, em setembro; b) 1,0 kg de sulfato de amônio, em novembro; c) $1,0 \mathrm{~kg}$ de sulfato de amônio, em janeiro. Também foi aplicado $5,0 \mathrm{~kg}$ de calcário dolomítico, em julho-agosto, sempre que o $\mathrm{pH}$ da solução do solo ficava inferior a 6,0. O ensaio foi encerrado em 1993, devido à carência de pessoal, equipamento e defensivos para o controle do ácaro da "leprose" dos citros.

A análise das flutuações de produção foi feita, comparando-se a produção de picos e vales consecutivos, independentemente do interstício de tempo existente entre eles. As reduções relativas de produção foram tomadas como sendo a redução de produção entre um pico e o vale seguinte, tendo-se como referência a produção do pico. Já as recuperações relativas de produção foram tomadas como sendo o aumento de produção entre um vale e o pico seguinte, tendo-se como referência a produção do vale.

A produção da laranjeira foi correlacionada com a idade do pomar e as precipitações mensais por meio de equações lineares múltiplas de regressão. A idade do pomar e as precipitações mensais foram consideradas como variáveis independentes e a produção como dependente. Para cada equação de regressão foi calculado um coeficiente de determinação, e o teste de Fischer foi usado para verificar sua significância estatística.

As precipitações que ocorreram durante o ano de florescimento, ou seja, no anterior à colheita, foram designadas como P1, P2, até P12, correspondendo aos meses de janeiro, fevereiro, até dezembro. As precipitações que ocorreram durante $o$ ano de colheita foram designadas como P13, P14, P15 e P16, correspondendo, respectivamente, aos meses de janeiro, fevereiro, março e abril.

A cultura desenvolveu-se sob condições térmicas e pluviométricas dentro dos limites considerados favoráveis ao seu desenvolvimento (Reuther, 1975). Também não apresentou relevantes problemas fitossanitários. As floradas ocorreram em agosto-setembro e os frutos alcançaram o estádio de colheita sempre em maio do ano seguinte. O cálculo da disponibilidade de água no solo, durante o ensaio, segundo o método de Thornthwaite \& Mather (1955) para $125 \mathrm{~mm}$ de capacidade de armazenamento de água no solo, revelou deficiência 
hídrica anual média de $3 \mathrm{~mm}$. Tal déficit caracteriza o local como apto para a cultura de laranja (São Paulo, 1974).

\section{RESULTADOS E DISCUSSÃO}

O curso das produções do pomar durante a realização do ensaio evidencia que houve picos e vales de produção, porém sem ocorrer o fenômeno da bianualidade até os 23 anos de idade do pomar (Fig.1). A partir daí, o fenômeno da bianualidade começou a se manifestar, possivelmente associado ao envelhecimento das plantas.

A não-manifestação da bianualidade acontece porque a laranjeira 'Westin', em Botucatu, atinge o ponto de maturação em maio, dois a três meses antes da nova florada. Como conseqüência, a floração e o crescimento dos frutos não competiriam por nutrientes, tornando a produção do ano seguinte independente daquela do ano anterior. Tubelis \& Salibe (1989, 1992) também não constataram a bianualidade nas produções de laranjeiras 'Hamlin' e 'Baianinha', até os 16 anos de idade do pomar, no mesmo local e período de ensaio.
Até os 23 anos de idade foram observadas quatro reduções de produção, que oscilaram entre $-37 \%$ e $-88 \%$ (Tabela 1). Essas reduções ocorreram de forma abrupta, de um ano para outro, com exceção do biênio 1986-1988, e são atribuídas às diversidades edáficas e climáticas, causas fisiológicas, pragas, doenças, controle do mato, entre outras. Reduções de produção, da mesma ordem de grandeza, também foram constatadas por Tubelis \& Salibe (1989) em pomar de laranjeira 'Hamlin' sobre porta-enxerto de limoeiro 'Cravo', no mesmo local e período de ensaio, até o $16^{\circ}$ ano de idade do pomar.

A maior redução de produção ocorreu de 1976 para 1977, na fase de pomar adulto (Tabela 1, Fig.1). A análise dos índices pluviométricos ocorridos em 1976 revelou que o período de abril a setembro foi extremamente chuvoso e atípico em relação aos índices médios do local. Tal fato deve ter prejudicado o pegamento da florada de agosto-setembro, corroborando as observações feitas por Agostini (1992) na Flórida. Os altos índices pluviométricos ocorridos inibiram a manifestação da estação de seca, causando o que foi observado por Bain (1949),

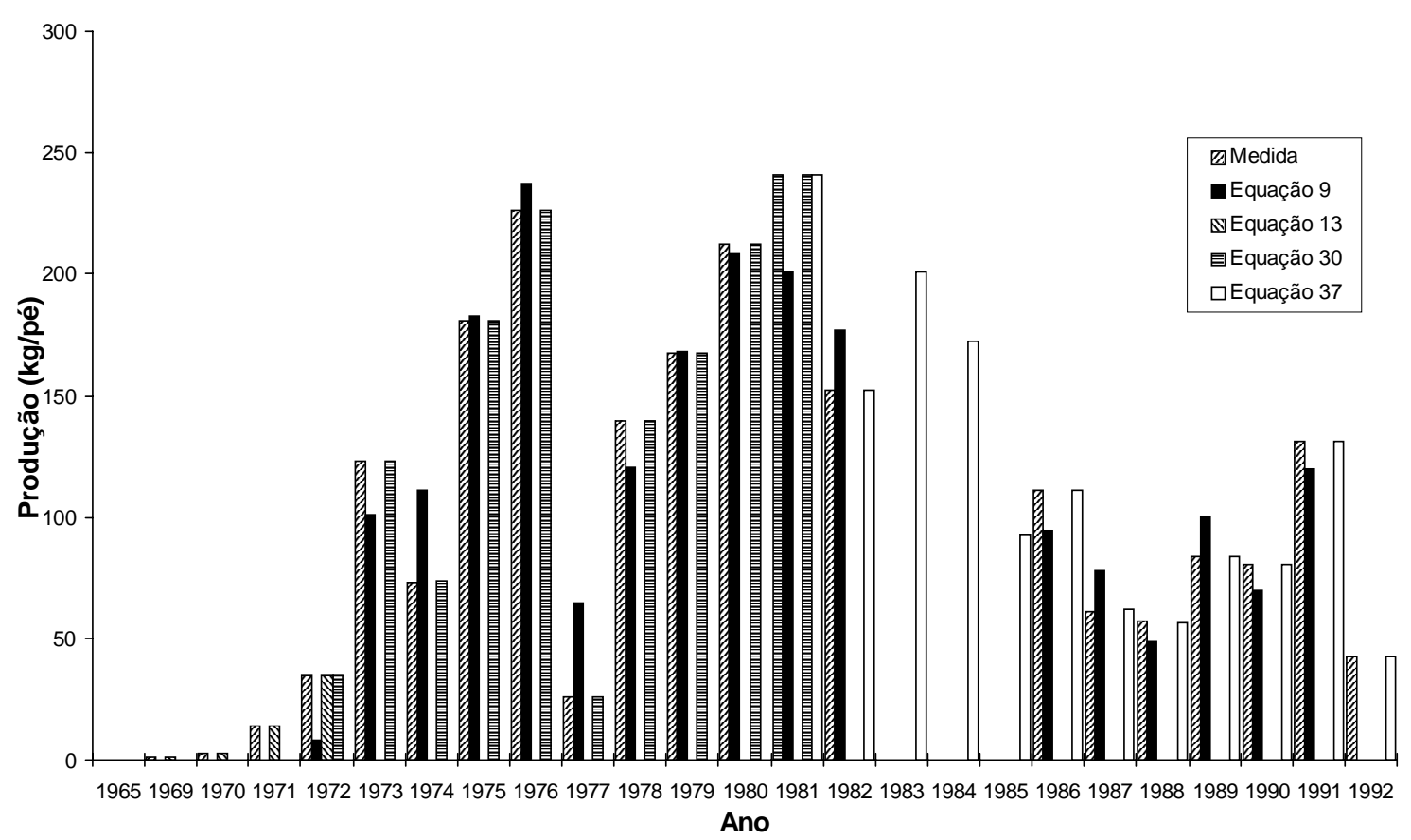

FIG. 1. Flutuação das produções medida e calculada de laranjeira 'Westin', sobre porta-enxerto de limoeiro 'Cravo' nas condições mesológicas do altiplano de Botucatu, SP. 
em Trinidad, que uma estação de seca, quando úmida, está associada com florada fraca que causa baixa produção de citros.

Foram registradas quatro recuperações de produção, que oscilaram entre $+47 \%$ e $+819 \%$ (Tabela 1), porém, antes dos 17 anos de idade, essas recuperações não se fizeram em um único ano. A duração do período e o valor de recuperação aumentaram com a intensidade da redução de produção que a antecedeu. Tais valores de recuperação de produção são superiores aos $+165 \%$ e $+363 \%$, observadas por Tubelis \& Salibe (1989), em laranjeira 'Hamlin' sobre limoeiro 'Cravo', até o 17o ano de idade do pomar, no mesmo local e período de ensaio. É provável que o porta-enxerto de limoeiro 'Cravo' tenha favorecido a laranjeira 'Westin'.

TABELA 1. Variações de produção de laranjeira 'Westin' sobre porta-enxerto de limoeiro 'Cravo', entre 1973 e 1982 e entre 1986 e 1992, nas condições mesológicas do altiplano de Botucatu, SP.

\begin{tabular}{|c|c|c|c|c|}
\hline \multirow[t]{2}{*}{ Ano } & \multirow{2}{*}{$\begin{array}{l}\text { Idade } \\
\text { (anos) }\end{array}$} & \multirow{2}{*}{$\begin{array}{c}\text { Produção } \\
\text { (kg/pé) }\end{array}$} & \multicolumn{2}{|c|}{ Variação de produção } \\
\hline & & & Período & $(\%)$ \\
\hline 1973 & 8 & 122,9 & & \\
\hline 1974 & 9 & 73,4 & 1973 a 1974 & -40 \\
\hline & & & 1974 a 1976 & +208 \\
\hline 1976 & 11 & 226,2 & & \\
\hline 1977 & 12 & 26,2 & 1976 a 1977 & -88 \\
\hline 1981 & 16 & 240,7 & 1977 a 1981 & +819 \\
\hline & & & 1981 a 1982 & -37 \\
\hline 1982 & 17 & 152,5 & & \\
\hline 1986 & 21 & 111,0 & & \\
\hline 1988 & 23 & 57,3 & 1986 a 1988 & -48 \\
\hline 1989 & 24 & 84,0 & 1988 a 1989 & +47 \\
\hline 1990 & 25 & 80,5 & 1989 a 1990 & -4 \\
\hline & & & 1990 a 1991 & +63 \\
\hline 1991 & 26 & 131,1 & 1992 ـ 1991 & -68 \\
\hline 1992 & 27 & 42,6 & & \\
\hline
\end{tabular}

De 1972 a 1982, os momentos de ocorrência dos picos e vales de produção da laranjeira 'Westin' não foram síncronos com os observados nas laranjeiras 'Hamlin' e 'Baianinha', considerando o mesmo local e período, e todas sobre mesmo portaenxerto. Houve coincidência de produção apenas nos picos em 1976 e 1981, e no vale em 1977.

Verificou-se que a produção do pomar apresentou a tendência de aumentar até o $16^{\circ}$ ano de idade, quando passou a decrescer. $\mathrm{O}$ cálculo das equações de regressão entre as produções do 70 ao $18^{\circ}$ e do $22^{\circ}$ ao $27 \underline{0}$ ano, evidenciou que as variáveis inverso e cubo da idade estão correlacionadas com as produções (Tabela 2). O fato de o inverso da idade do pomar mostrar-se inversamente correlacionado com a produção, indica que a produção do pomar aumentou com a idade das plantas, pelo fato de as plantas aumentarem de tamanho com o passar do tempo. Fato semelhante foi observado por Tubelis \& Salibe $(1989,1992)$ analisando o efeito da idade do pomar na produtividade das laranjeiras 'Hamlin' e 'Baianinha'.

A idade do pomar foi capaz de explicar 39,9\% da variação de produção do pomar (Equação 1). Esse valor é maior que os $18,4 \%$ observados em relação à laranjeira 'Hamlin' (Tubelis \& Salibe, 1989), e os $28,7 \%$ observados na laranjeira 'Baianinha' (Tubelis \& Salibe, 1992), para o mesmo local e período de ensaio. Tais números mostram que a idade da planta confere maior estabilidade de produção à laranjeira 'Westin', do que às 'Baianinha' e 'Hamlin', quando enxertadas em limoeiro 'Cravo'.

O cálculo dos coeficientes de correlação, entre as produções do pomar, nos períodos de 1972 a 1982 e de 1986 a 1992, com as precipitações mensais, revelou que as produções mostraram-se negativamente correlacionadas com as precipitações que ocorreram nos meses de fevereiro e março e maio a outubro do ano anterior à colheita, e fevereiro e março do ano da colheita. As precipitações ocorridas nos meses de janeiro, abril, novembro e dezembro do ano anterior à colheita, e janeiro e abril do ano da colheita, mostraram-se correlacionadas positivamente com a produção do pomar. $\mathrm{O}$ fato de as precipitações de determinados meses provocarem redução de produção no pomar foi constatado anteriormente por Tubelis \& Salibe $(1989,1992)$ 
quando analisaram o efeito das precipitações em pomares de laranjeiras 'Hamlin' e 'Baianinha', sobre porta-enxerto de limoeiro 'Cravo', em mesmo local e período. As precipitações diminuíram a produção do pomar, simultaneamente nas três copas, apenas nos meses de junho e setembro do ano anterior à colheita, e março do ano da colheita. E aumentaram simultaneamente as produções dos referidos pomares apenas no mês de abril do ano da colheita. Esses fatos revelam que as exigências hídricas dos três pomares diferiram entre si.

Os resultados do cálculo das equações lineares múltiplas de regressão, entre as produções de 1972 a 1982 e de 1986 a 1992 e as variáveis idade do pomar e totais mensais de precipitação, estão resumidos na Tabela 2. Todas as equações inseridas apresentam coeficiente de determinação estatisticamente significante a $1 \%$ de probabilidade de erro. Verificou-se que as precipitações que ocorreram nos meses de abril, maio, junho, setembro e dezembro, do ano anterior à colheita, e abril, do ano da colheita, foram as que mais influenciaram na produção do pomar. O sinal dos coeficientes angulares revela que apenas as precipitações ocorridas em abril do ano da colheita, e dezembro do ano anterior à colheita causaram aumento de produção do pomar. Prova- velmente, as chuvas ocorridas em abril contribuíram para aumentar a turgescência dos frutos, que eram colhidos no mês seguinte (maio).

As chuvas ocorridas em abril do ano da colheita também provocaram aumento de produção nas laranjeiras 'Hamlin' e 'Baianinha', sobre porta-enxerto de limoeiro 'Cravo' no mesmo local e período de ensaio (Tubelis \& Salibe, 1989, 1992).

As chuvas de dezembro estão associadas positivamente com a produção porque nesse mês a planta ajusta sua produção à disponibilidade de água no solo com a derrubada de frutos. Trata-se do fenômeno conhecido como queda de dezembro, que na Flórida, USA, é conhecido como "june drop".

As chuvas que ocorreram em junho e setembro do ano da florada contribuíram para reduzir a produção do pomar no ano seguinte. Resultados semelhantes foram observados em pomares de laranjeiras 'Hamlin' e 'Baianinha' sobre porta-enxerto de limoeiro 'Cravo' no mesmo local e período de ensaio (Tubelis \& Salibe, 1989, 1992).

Comparando-se os meses que entram nas equações de regressão da Tabela 2 com os que entraram em equações similares, obtidas por Tubelis \& Salibe (1989, 1992) para laranjeiras 'Hamlin' e 'Baianinha', verifica-se que há pouca coincidência,

TABELA 2. Coeficientes linear, angular e de determinação das equações lineares múltiplas de regressão entre a produção de laranjeira 'Westin' sobre porta-enxerto de limoeiro 'Cravo'(w/c), idade do pomar (I) e precipitação mensal (P), expressos, respectivamente, em kg/pé, anos e mm, nos períodos de 1972 a 1982 e de 1986 a 1992 , referente à fase de pomar adulto-senescente, nas condições mesológicas do altiplano de Botucatu, SP.

\begin{tabular}{|c|c|c|c|c|c|c|c|c|c|c|}
\hline \multirow[t]{2}{*}{ Variáveis } & \multicolumn{8}{|c|}{$Y=a+b X_{1}+c X_{2}+d X_{3}+e X_{4}$} & \multirow[t]{2}{*}{$r^{2}$} & \multirow[t]{2}{*}{ Equação } \\
\hline & $\mathrm{a}$ & $\mathrm{b}$ & $\mathrm{c}$ & $\mathrm{d}$ & $\mathrm{e}$ & $\mathrm{f}$ & $\mathrm{g}$ & $\mathrm{h}$ & & \\
\hline $\mathrm{W} / \mathrm{C}=\mathrm{f}\left(1 / \mathrm{I}, \mathrm{I}^{3}\right)$ & 316,7 & $-1732,6$ & $-0,01023$ & & & & & & $0,3992^{*}$ & 1 \\
\hline $\mathrm{W} / \mathrm{C}=\mathrm{f}\left(1 / \mathrm{I}, \mathrm{I}^{3}, \mathrm{P} 5\right)$ & 378,6 & $-2010,3$ & $-0,01090$ & $-0,472$ & & & & & $0,5895 * *$ & 2 \\
\hline $\mathrm{W} / \mathrm{C}=\mathrm{f}\left(1 / \mathrm{I}, \mathrm{I}^{3}, \mathrm{P} 5, \mathrm{P} 16\right)$ & 355,1 & $-2047,0$ & $-0,01183$ & $-0,576$ & $+0,552$ & & & & $0,7047 * *$ & 3 \\
\hline $\mathrm{W} / \mathrm{C}=\mathrm{f}\left(1 / \mathrm{I}, \mathrm{I}^{3}, \mathrm{P} 4, \mathrm{P} 5, \mathrm{P} 16\right)$ & 447,4 & $-2504,5$ & $-0,01291$ & $-0,541$ & $-0,724$ & $+0,556$ & & & $0,8088^{* *}$ & 4 \\
\hline $\mathrm{W} / \mathrm{C}=\mathrm{f}\left(1 / \mathrm{I}, \mathrm{I}^{3}, \mathrm{P} 4, \mathrm{P} 5, \mathrm{P} 6, \mathrm{P} 16\right)$ & 451,8 & $-2416,1$ & $-0,01293$ & $-0,502$ & $-0,629$ & $-0,301$ & $+0,502$ & & $0,8492 * *$ & 5 \\
\hline $\mathrm{W} / \mathrm{C}=\mathrm{f}\left(1 / \mathrm{I}, \mathrm{I}^{3}, \mathrm{P} 4, \mathrm{P} 5, \mathrm{P} 6, \mathrm{P} 9, \mathrm{P} 16\right)$ & 414,3 & $-2030,7$ & $-0,01266$ & $-0,279$ & $-0,381$ & $-0,408$ & $-0,510$ & $+0,792$ & $0,8865 * *$ & 6 \\
\hline $\mathrm{W} / \mathrm{C}=\mathrm{f}\left(1 / \mathrm{I}, \mathrm{I}^{3}, \mathrm{P} 5, \mathrm{P} 6, \mathrm{P} 9, \mathrm{P} 16\right)$ & 367,6 & $-1712,4$ & $-0,01218$ & $-0,225$ & $-0,470$ & $-0,714$ & $+0,903$ & & $0,8678 * *$ & 7 \\
\hline $\mathrm{W} / \mathrm{C}=\mathrm{f}\left(1 / \mathrm{I}, \mathrm{I}^{3}, \mathrm{P} 6, \mathrm{P} 9, \mathrm{P} 16\right)$ & 355,4 & $-1549,7$ & $-0,01198$ & $-0,570$ & $-0,900$ & $+0,943$ & & & $0,8430 * *$ & 8 \\
\hline $\mathrm{W} / \mathrm{C}=\mathrm{f}\left(1 / \mathrm{I}, \mathrm{I}^{3}, \mathrm{P} 6, \mathrm{P} 9, \mathrm{P} 12, \mathrm{P} 16\right)$ & 317,2 & $-1664,9$ & $-0,01263$ & $-0,571$ & $-0,940$ & $+0,199$ & $+1,057$ & & $0,8948 * *$ & 9 \\
\hline
\end{tabular}


evidenciando que o comportamento das plantas ao regime pluvial não é o mesmo. Tal fato deve ser levado em consideração principalmente ao se implantar um sistema de irrigação suplementar para corrigir as flutuações climáticas.

Todas as equações apresentadas na Tabela 2 poderiam ser usadas na estimativa de safra do pomar, e também na estimativa do aumento de produtividade do pomar quando se empregasse irrigação suplementar. A estimativa mais precoce de safra poderia ser feita em fins de maio mediante a Equação 2. As variáveis nela envolvidas foram capaz de explicar 58,95\% da variação de produção das plantas durante o período de ensaio. Por meio dessa equação, a safra do pomar poderia ser conhecida no início de junho, onze meses antes da época de colheita. A estimativa de safra mediante as Equações 3 a 9 exigiria o conhecimento do valor da precipitação do mês de abril do ano da colheita. Tal fato faz com que a estimativa venha a ser conhecida muito próximo da época de colheita, quando já se pode saber o real valor da safra. Para contornar essa dificuldade técnica, pode-se empregar, nas referidas equações, o valor médio das precipitações do mês de abril. Usando-se esse artifício, a estimativa de safra da cultura poderia ser feita em maio, pela Equação 4, em junho, pela Equação 5, em setembro, pelas Equações 6, 7 ou 8, e em dezembro, pela Equação 9.

Dentre todas as equações apresentadas, a de número 9 foi a que revelou o maior coeficiente de determinação $\left(r^{2}=0,8948\right)$. Com o auxílio dessa equação, estimou-se a safra do pomar durante os períodos de 1972 a 1982 e de 1986 a 1992. Com tais valores e com os valores medidos de produção elaborou-se a Fig.1. Verifica-se que houve sincronismo quase perfeito entre as produções medidas e estimadas. O desvio percentual médio, expresso em módulo, entre os valores medidos e estimados foi de 26,2\%. Esse valor é superior ao de $20,9 \%$ obtido com a laranjeira 'Baianinha' (Tubelis \& Salibe, 1992) e muito superior aos 4,0\% obtidos com a laranjeira 'Hamlin', ambas sobre porta-enxerto de limoeiro 'Cravo', no período de 1972 a 1982, no mesmo local de ensaio. Pelo fato de os desvios obtidos serem muito elevados, decidiu-se dividir o período de produção do pomar em três subperíodos: do $3^{\text {o }}$ ao $7^{0}$ ano (pomar juvenil), do 70 ao $16^{\circ}$ ano (pomar adulto) e do $16^{\circ}$ ao $27^{\circ}$ ano (pomar senescente) (Fig.1).

Os resultados do cálculo das equações lineares múltiplas de regressão, entre a produção das laranjeiras no período de 1968 a 1972 e as variáveis idade do pomar e precipitações mensais, estão contidos na Tabela 3. As Equações 11 a 13 apresentaram coeficiente de determinação estatisticamente significante a $1 \%$ de probabilidade. Todas as equações obtidas poderiam ser usadas na estimativa de safra da cultura. Pela Equação 12, verifica-se que a idade do pomar foi responsável por $99,36 \%$ da variação de produção das plantas, indicando que no período juvenil, a produção do pomar depende, quase que exclusivamente, do tamanho das plantas. Pela Equação 13, verifica-se que apenas as precipitações que ocorreram no mês de julho do ano anterior à colheita influenciaram na produção. Contudo, tal influência foi muito pequena. $\mathrm{O}$ fato de no período juvenil a produção do pomar ter sido pouco influenciada pelo regime pluvial, deve residir na condição de o sistema radicular das plantas estar em expansão e não haver explorado todo o volume de solo disponível. Nessa situação, a disponibilidade de água no solo seria maior do que a necessidade de água das plantas e, portanto, não ocorreriam restrições hídricas. O desvio percentual médio entre os valores de produção medidos e estimados por meio da Equação 13, variou entre os limites de $-0,35 \%$ e $+0,08 \%$, com valor médio, expresso em módulo, de $0,12 \%$.

Os resultados do cálculo das equações lineares múltiplas de regressão, entre a produção das plantas no período de 1972 a 1981 , ou seja, do 70 ao $16^{\circ}$ ano de idade do pomar, e as variáveis idade do pomar e totais mensais de precipitação, estão contidos na Tabela 4. As Equações 21 e 22 apresentaram coeficiente de determinação estatisticamente significante a $5 \%$ de probabilidade, e as demais, a $1 \%$ de probabilidade. Todas as equações obtidas poderiam ser usadas na estimativa de safra da cultura. A estimativa mais precoce de safra poderia ser feita no início de junho do ano anterior à colheita, onze meses antes do período de colheita, empregando-se as Equações 22, 23, 24, 25 ou 26. A estimativa de safra também poderia ser feita em feve- 
reiro e em abril do ano da colheita pelas Equações 27 ou 28 e 29 ou 30, respectivamente. Dentre todas as equações apresentadas, a de número 30 foi a que apresentou o maior coeficiente de determinação $\left(r^{2}=0,9999\right)$. Com ela foram estimadas as produções do pomar para o período de 1972 a 1981 . Constatou-se sincronismo perfeito entre as produções medidas e calculadas (Fig. 1). O desvio entre essas produções variou entre os limites de $-0,36 \%$ a $+0,38 \%$, com valor médio, expresso em módulo, de $0,17 \%$. Tal fato revela que a equação 30 conduz a melhores valores de estimativa de produção do que a Equação 9. A aplicação da Equação 30 para a estimativa da produção de 1997 revelou que os altos índices pluviométricos ocorridos em abril e maio de 1996 foram os principais responsáveis pela baixa produção ocorrida.

Os resultados do cálculo das equações lineares múltiplas de regressão, entre a produção das plantas nos períodos de 1981 e 1982 e de 1986 a 1992 , ou seja, do $16^{\circ}$ e $17^{\circ}$ e do $21^{\circ}$ ao $27^{\circ}$ ano de idade do pomar, e as variáveis idade do pomar e precipitações mensais, estão contidos na Tabela 5. As Equações 31 a 35 apresentaram coeficientes de determinação estatisticamente significante a $1 \%$ de probabilidade. Todas as equações obtidas poderiam ser usadas na estimativa de safra da cultura. A estimativa mais precoce de safra poderia ser feita no início de abril do ano da colheita, um mês antes do início da colheita, com o emprego das Equações 32 a 37.
A estimativa de safra da cultura poderia ser antecipada para o início de outubro do ano anterior à colheita, sete meses antes do início da colheita, adotando-se o artifício de substituir as variáveis P13 e P15, nas Equações 35 a 37, pelos seus respectivos valores médios. As estimativas teriam que ser refeitas à medida que os valores reais dessas variáveis fossem sendo obtidos. Dentre todas as equações apresentadas, a de número 37 foi a que apresentou o maior coeficiente de determinação $\left(r^{2}=0,9999\right)$. Com ela foram estimadas as produções das plantas para o período de 1981 a 1992. Constatou-se sincronismo perfeito entre as produções medidas e estimadas. O desvio entre essas produções variou entre os limites de $-1,56 \%$ a $+1,25 \%$, com valor médio, expresso em módulo, de $0,46 \%$. Tal fato revela que a Equação 37 conduz a valores mais precisos de estimativa do que os obtidos com a Equação 9.

Verifica-se na Fig. 1 que o desvio existente entre os valores medidos e estimados pelas Equações 13,30 e 37 são muito pequenos, quando comparados com os obtidos com o emprego da Equação 9. Esse fato comprova a necessidade de se dividir o período de produção do pomar em subperíodos para se obter melhor estimativa climática das produções.

Nas condições mesológicas do altiplano de Botucatu é possível obterem-se aumentos de produção com a aplicação de irrigação suplementar. Para a fase pomar juvenil, adulto e senescente au-

TABELA 3. Coeficientes linear, angular e de determinação das equações lineares múltiplas de regressão entre a produção de laranjeira 'Westin' sobre porta-enxerto de limoeiro 'Cravo'(w/c), idade do pomar (I) e precipitação mensal (P), expressos, respectivamente, em $\mathrm{kg} /$ pé, anos e mm, no período de 1968 a 1972, referente à fase de pomar juvenil, nas condições mesológicas do altiplano de Botucatu, SP.

\begin{tabular}{|c|c|c|c|c|c|c|}
\hline \multirow[t]{2}{*}{ Variáveis } & \multicolumn{4}{|c|}{$\mathrm{Y}=\mathrm{a}+\mathrm{b} \mathrm{X}_{1}+\mathrm{c} \mathrm{X}_{2}+\mathrm{d} \mathrm{X}_{3}$} & \multirow[t]{2}{*}{$r^{2}$} & \multirow[t]{2}{*}{ Equação } \\
\hline & $\mathrm{a}$ & $\mathrm{b}$ & $\mathrm{c}$ & $\mathrm{d}$ & & \\
\hline $\mathrm{W} / \mathrm{C}=\mathrm{f}\left(\mathrm{I}^{3}\right)$ & $-6,6$ & $+0,1103$ & & & $0,9287 * *$ & 11 \\
\hline $\mathrm{W} / \mathrm{C}=\mathrm{f}\left(\mathrm{I}^{2}, \mathrm{I}^{3}\right)$ & $+10,3$ & $-2,202$ & $+0,3846$ & & $0,9936 * *$ & 12 \\
\hline $\mathrm{W} / \mathrm{C}=\mathrm{f}\left(\mathrm{I}^{2}, \mathrm{I}^{3}, \mathrm{P} 7\right)$ & $+21,7$ & $-3,308$ & $+0,5192$ & $-0,064$ & $0,9999 * *$ & 13 \\
\hline
\end{tabular}


TABELA 4. Coeficientes linear, angular e de determinação das equações lineares múltiplas de regressão entre a produção de laranjeira 'Westin' sobre porta-enxerto de limoeiro 'Cravo'(w/c), idade do pomar (I) e precipitação mensal (P), expressos, respectivamente, em kg/pé, anos e mm, no período de 1972 a 1981, referente à fase de pomar adulto, nas condições mesológicas do altiplano de Botucatu, SP.

\begin{tabular}{|c|c|c|c|c|c|c|c|c|c|c|c|}
\hline \multirow[t]{2}{*}{ Variáveis } & \multicolumn{9}{|c|}{$\mathrm{Y}=\mathrm{a}+\mathrm{b} \mathrm{X}_{1}+\mathrm{c} \mathrm{X}_{2}+\mathrm{d} \mathrm{X}_{3}+\mathrm{e} \mathrm{X}_{4}+\mathrm{f} \mathrm{X}_{5}+\mathrm{g} \mathrm{X}_{6}+\mathrm{h} \mathrm{X}_{7}+\mathrm{i} \mathrm{X}_{8}$} & \multirow[t]{2}{*}{$r^{2}$} & \multirow[t]{2}{*}{ Equação } \\
\hline & $\mathrm{a}$ & $\mathrm{b}$ & $\mathrm{c}$ & $\mathrm{d}$ & $\mathrm{e}$ & $\mathrm{f}$ & $\mathrm{g}$ & $\mathrm{h}$ & $\mathrm{i}$ & & \\
\hline $\mathrm{W} / \mathrm{C}=\mathrm{f}\left(\mathrm{I}^{2}\right)$ & 45,7 & $+0,6894$ & & & & & & & & $0,3887 *$ & 21 \\
\hline $\mathrm{W} / \mathrm{C}=\mathrm{f}\left(\mathrm{I}^{2}, \mathrm{P} 5\right)$ & 75,1 & $+0,8111$ & $-0,624$ & & & & & & & $0,6573 *$ & 22 \\
\hline $\mathrm{W} / \mathrm{C}=\mathrm{f}\left(\mathrm{I}^{2}, \mathrm{P} 4, \mathrm{P} 5\right)$ & 112,2 & $+1,0158$ & $-0,732$ & $-0,826$ & & & & & & $0,8083 * *$ & 23 \\
\hline $\mathrm{W} / \mathrm{C}=\mathrm{f}\left(\mathrm{I}^{2}, \mathrm{P} 2, \mathrm{P} 4, \mathrm{P} 5\right)$ & 75,7 & $+1,0768$ & $+0,357$ & $-1,068$ & $-0,982$ & & & & & $0,9348 * *$ & 24 \\
\hline $\mathrm{W} / \mathrm{C}=\mathrm{f}\left(\mathrm{I}^{2}, \mathrm{I}^{-1}, \mathrm{P} 2, \mathrm{P} 4, \mathrm{P} 5\right)$ & 311,2 & $+0,4938$ & $-1657,6$ & $+0,385$ & $-1,092$ & $-1,016$ & & & & $0,9694 * *$ & 25 \\
\hline $\mathrm{W} / \mathrm{C}=\mathrm{f}\left(\mathrm{I}^{-1}, \mathrm{P} 2, \mathrm{P} 4, \mathrm{P} 5\right)$ & 488,3 & $-2865,0$ & $+0,398$ & $-1,060$ & $-1,013$ & & & & & $0,9480 * *$ & 26 \\
\hline $\mathrm{W} / \mathrm{C}=\mathrm{f}\left(\mathrm{I}^{-1}, \mathrm{P} 2, \mathrm{P} 4, \mathrm{P} 5, \mathrm{P} 13\right)$ & 470,8 & $-2934,9$ & $+0,429$ & $-1,223$ & $-1,100$ & $+0,159$ & & & & $0,9942 * *$ & 27 \\
\hline $\mathrm{W} / \mathrm{C}=\mathrm{f}\left(\mathrm{I}^{-1}, \mathrm{P} 2, \mathrm{P} 4, \mathrm{P} 5, \mathrm{P} 11, \mathrm{P} 13\right)$ & 486,5 & $-3015,6$ & $+0,474$ & $-1,277$ & $-1,137$ & $-0,556$ & $+0,156$ & & & $0,9976^{* *}$ & 28 \\
\hline $\mathrm{W} / \mathrm{C}=\mathrm{f}\left(\mathrm{I}^{-1}, \mathrm{P} 2, \mathrm{P} 4, \mathrm{P} 5, \mathrm{P} 11, \mathrm{P} 13, \mathrm{P} 15\right)$ & 483,7 & $-3099,8$ & $+0,497$ & $-1,377$ & $-1,171$ & $-0,053$ & $+0,190$ & $+0,047$ & & $0,9998 * *$ & 29 \\
\hline $\mathrm{W} / \mathrm{C}=\mathrm{f}\left(\mathrm{I}^{-1}, \mathrm{P} 2, \mathrm{P} 4, \mathrm{P} 5, \mathrm{P} 7, \mathrm{P} 11, \mathrm{P} 13, \mathrm{P} 15\right)$ & 477,8 & $-3022,3$ & $+0,516$ & $-1,375$ & $-1,107$ & $-0,114$ & $-0,041$ & $+0,172$ & $+0,042$ & $0,9999 * *$ & 30 \\
\hline
\end{tabular}

TABELA 5. Coeficientes linear, angular e de determinação das equações lineares múltiplas de regressão entre a produção de laranjeira 'Westin' sobre porta-enxerto de limoeiro 'Cravo'(w/c), idade do pomar (I) e precipitação mensal (P), expressos, respectivamente, em kg/pé, anos e mm, para o período de 1981 e 1982 e de 1986 a 1992, referente à fase de pomar senescente, nas condições mesológicas do altiplano de Botucatu, SP.

\begin{tabular}{|c|c|c|c|c|c|c|c|c|c|c|}
\hline \multirow[t]{2}{*}{ Variáveis } & \multicolumn{8}{|c|}{$\mathrm{Y}=\mathrm{a}+\mathrm{b} \mathrm{X}_{1}+\mathrm{c} \mathrm{X}_{2}+\mathrm{d} \mathrm{X}_{3}+\mathrm{e} \mathrm{X}_{4}+\mathrm{f} \mathrm{X}_{5}+\mathrm{g} \mathrm{X}_{6}+\mathrm{h} \mathrm{X}_{7}$} & \multirow[t]{2}{*}{$\mathrm{r}^{2}$} & \multirow[t]{2}{*}{ Equação } \\
\hline & $\mathrm{a}$ & $\mathrm{b}$ & $\mathrm{c}$ & $\mathrm{d}$ & $\mathrm{e}$ & $\mathrm{f}$ & $\mathrm{g}$ & $\mathrm{h}$ & & \\
\hline $\mathrm{W} / \mathrm{C}=\mathrm{f}(\ln \mathrm{I})$ & 935,7 & $-268,1$ & & & & & & & $0,6260 * *$ & 31 \\
\hline $\mathrm{W} / \mathrm{C}=\mathrm{f}(\ln \mathrm{I}, \mathrm{P} 15)$ & 1223,9 & $-379,4$ & $+0,267$ & & & & & & $0,7692 * *$ & 32 \\
\hline $\mathrm{W} / \mathrm{C}=\mathrm{f}(\ln \mathrm{I}, \mathrm{P} 13, \mathrm{P} 15)$ & 1064,4 & $-346,6$ & $+0,207$ & $+0,272$ & & & & & $0,8648 * *$ & 33 \\
\hline $\mathrm{W} / \mathrm{C}=\mathrm{f}(\ln \mathrm{I}, \mathrm{P} 2, \mathrm{P} 13, \mathrm{P} 15)$ & 999,7 & $-369,5$ & $+0,372$ & $+0,376$ & $+0,264$ & & & & $0,9724 * *$ & 34 \\
\hline $\mathrm{W} / \mathrm{C}=\mathrm{f}(\ln \mathrm{I}, \mathrm{P} 2, \mathrm{P} 9, \mathrm{P} 13, \mathrm{P} 15)$ & 1039,4 & $-390,4$ & $+0,288$ & $+0,514$ & $+0,421$ & $+0,243$ & & & $0,9937 * *$ & 35 \\
\hline $\mathrm{W} / \mathrm{C}=\mathrm{f}(\ln \mathrm{I}, \mathrm{P} 2, \mathrm{P} 3, \mathrm{P} 9, \mathrm{P} 13, \mathrm{P} 15)$ & 1060,2 & $-397,4$ & $+0,270$ & $+0,047$ & $+0,453$ & $+0,424$ & $+0,236$ & & $0,9984 * *$ & 36 \\
\hline $\mathrm{W} / \mathrm{C}=\mathrm{f}(\ln \mathrm{I}, \mathrm{P} 1, \mathrm{P} 2, \mathrm{P} 3, \mathrm{P} 9, \mathrm{P} 13, \mathrm{P} 15)$ & 1804,0 & $-404,1$ & $-0,032$ & $+0,275$ & $+0,036$ & $+0,456$ & $+0,432$ & $+0,258$ & $0,9999 * *$ & 37 \\
\hline
\end{tabular}


mentos de produção poderiam ser alcançados com irrigação suplementar, respectivamente, nos meses de julho do ano anterior à colheita; fevereiro do ano anterior à colheita e janeiro e fevereiro do ano da colheita; e nos meses de fevereiro, março e setembro do ano anterior à colheita e janeiro e março do ano da colheita. Os aumentos de produção com aplicação de irrigação suplementar poderiam ser estimados pelas Equações 13, 24 a 30 e 32 a 37.

\section{CONCLUSÕES}

1. A produção do pomar está correlacionada com a idade do pomar e com os valores mensais de precipitação que ocorrem nos 16 meses que antecedem a colheita.

2. A estimativa de safra do pomar, fase pomar adulto, pode ser feita em junho do ano anterior à colheita, 11 meses antes da colheita.

3. A divisão da fase adulto-senescente do período de produção do pomar, nas fases adulto e senescente, reduz o erro da estimativa da produção.

4. A produtividade do pomar pode ser aumentada aplicando-se irrigação suplementar no meses de julho do ano anterior à colheita, em pomar na fase juvenil; nos meses de fevereiro do ano anterior à colheita e de janeiro e fevereiro do ano da colheita, na fase adulto; e nos meses de fevereiro, março e setembro do ano anterior à colheita e de janeiro e março do ano da colheita, na fase senescente.

5. O fenômeno da bianualidade nas produções ocorre apenas após o $23^{\circ}$ ano de idade do pomar.

6. Índices pluviométricos excessivos no período de abril a setembro causam expressivas quedas de produção no ano seguinte.

\section{AGRADECIMENTOS}

Ao Conselho Nacional de Desenvolvimento Científico e Tecnológico (CNPq), pela concessão de Bolsa de Pesquisa para o desenvolvimento do presente trabalho.

\section{REFERENCIAS}

AGOSTINI, J.P. Etiology and epidemiology of postbloom fruit drops of citrus. Gainesville: Univ. of Florida, 1992. 152p. Ph.D. Dissertation.

BAIN, F.M. Citrus and climate. The California Citrograph, Los Angeles, v.34, n.9, p.382, 412-414, 426, 448, July 1949.

DU PLESSIS, S.F. Crop forecasting for navels in South Africa. Proceedings of the Florida State Horticultural Society, Winter Haven, v.96, p.40-43, 1983.

GALlO, J.R.; RODRIGUEZ, O.; CAMARGO, A.P.; IGUE, T. Variações anuais na produção de frutas e concentração de macronutrientes em folhas de citros, relacionadas ao balanço hídrico meteorológico e adubação, no período de 1957 a 1975. Bragantia, Campinas, v.36, n.27, p.271-289, 1977.

REUTHER, W. Potencial of citrus culture in the Amazon Valley. In: INTERNATIONAL SYMPOSIUM ON ECOPHYSIOLOGY OF TROPICAL CROPS, 1975, Manaus. Ilhéus: CEPLAC, 1975. v.2., Ch.13, p.1-31. Preprints of papers.

SÃO PAULO. Secretaria de Agricultura. Zoneamento agrícola do Estado de São Paulo. São Paulo, 1974. v. $1,165 p$.

THORNTHWAITE, C.W.; MATHER, J.R. The water balance. Centerton: Laboratory of Climatology, 1955. 104p. (Publication in Climatology, 8).

TUBELIS, A.; SALIBE, A.A. Relações entre a produção de laranjeira 'Baianinha', a idade e as precipitações mensais no altiplano de Botucatu, SP. Pesquisa Agropecuária Brasileira, Brasília, v.27, n.5, p.703707, maio 1992.

TUBELIS, A.; SALIBE, A.A. Relações entre a produção de laranjeira 'Hamlin' e as precipitações mensais no altiplano de Botucatu. Pesquisa Agropecuária Brasileira, Brasília, v.24, n.7, p.801-806, jul. 1989. 